\title{
OS CONFORTOS E DESCONFORTOS REFERENTES AO CUIDADO CONSIGO E COTIDIANO VIVENCIADOS POR FAMILIARES DE ENTES HOSPITALIZADOS
}

\author{
Mirella Almeida de Souza ${ }^{1}$; Kátia Santana Freitas ${ }^{2}$; \\ 1. Graduanda em Psicologia, Bolsista PIBIC/Fapesb, integrante do Núcleo Interdisciplinar de Pesquisas e Estudos em \\ Saúde, Universidade Estadual de Feira de Santana, e-mail:mirella-almeida3@hotmail.com \\ 2. Orientador, Professor Adjunto B do Departamento de Saúde, Líder do Núcleo Interdisciplinar de Pesquisas e \\ Estudos em Saúde (NIPES/DSAU/UEFS) e-mail: freitaskatia@yahoo.com.br
}

PALAVRAS-CHAVE: Conforto, desconforto e familiares

\section{INTRODUÇÃO}

A hospitalização de um parente traz significativas repercussões aos hábitos de vida e papéis desempenhados pela família, podendo levar a desestruturação na dinâmica do grupo familiar. Estratégias de enfrentamento têm sido utilizadas para auxiliar a reorganização da família para que o equilíbrio venha a ser alcançado. $\mathrm{O}$ ajuste a nova situação, de modo geral, vem acompanhado de sofrimento e conflitos potencializados pela abdicação de si para o cuidado contínuo ao ente hospitalizado, fazendo com que os fatores externos a esse evento como os estudos, relacionamentos conjugais, atenção aos filhos e família, lazeres, cuidado com a saúde e aparência sejam interrompidos e deixados em segundo plano (PASSOS, PEREIRA, NITCHKE, 2015).

No contexto hospitalar, conforto pode ser definido como poder cuidar de si mesmo, manter as atividades habituais e a vida familiar. Mas, dificilmente, alcançado quando a atenção está centralizada no parente hospitalizado, na possibilidade de perda e demandas da hospitalização. A rotina do hospital dificulta a manutenção das necessidades básicas de cuidado integral consigo mesmo, devido à rotina hospitalar que intervêm no sono, repouso, nutrição e vida familiar, que deixam de ocorrer como antes da hospitalização e passam a se manifestar através da falta de apetite, dificuldade de descansar devido a ausência do lar, tensões e preocupações (FREITAS, MENEZES, MUSSI, 2015).

Tendo em vista as vulnerabilidades no campo fisiológico e psicológico enfrentado pelas famílias de pessoas hospitalizadas, bem como a importância da saúde e os cuidados dispensados a si mesmos, o presente plano de trabalho objetiva analisar o nível de conforto associado ao cuidado à saúde que familiares têm tido consigo mesmos 
durante a hospitalização de familiares na UTI, além de propor estratégias de autocuidado e coping para o melhor enfrentamento do processo hospitalização de familiares. Para isso, será considerada a dimensão "Integração consigo e o cotidiano" presente na ECONF, que abrange sete itens que representam o conforto vinculado ao cuidar de si, ajudar o ente e dar continuidade à vida familiar, como antes do ingresso do familiar na UTI.

\section{MATERIAL E MÉTODOS OU METODOLOGIA (ou equivalente)}

O presente plano de trabalho esteve vinculado ao projeto de Construção e Validação de uma Escala de Conforto para Familiares de Pessoas em Estado Crítico de Saúde (ECONF) validada para medir o nível de conforto de familiares de pessoas hospitalizadas na UTI (FREITAS, MENEZES, MUSSI, 2015). O plano, portanto, pode ratificar a eficiência da ECONF no que tange a sua aplicação e a avaliação do nível de cuidado à saúde que as famílias têm tido consigo mesmos durante o processo de internação de parentes na UTI.

A aplicação da ECONF foi realizada por meio uma entrevista que contém questões sociodemográficas (sexo, estado civil, nível de escolaridade e religião). Além disso, foram levantadas questões sobre experiências anteriores em UTI e se a pessoa entrevistada morava com o familiar hospitalizado. No que tange ao internamento na UTI foram abordadas questões como o diagnóstico médico do internado, tempo de hospitalização do familiar, gravidade da doença, visitas realizadas durante $o$ internamento, suporte da equipe multiprofissional - fatores estruturais do hospital enquanto elementos colaboradores para a promoção de conforto a família.

\section{RESULTADOS E/OU DISCUSSÃO (ou Análise e discussão dos resultados)}

O estudo foi realizado com 374 familiares de pacientes internados em duas Unidades de Terapia Intensiva (UTI), pertencente a um hospital público de Feira de Santana. Dentre eles, $65,8 \%$ homens e $34,2 \%$ mulheres. No que se refere aos dados demográficos constatou-se que a maioria deles eram casados $(43,3 \%)$, pertencentes a religião católica $(54,0 \%)$, que cursaram o ensino médio $(55,6 \%)$ e ativos no mercado de trabalho $(43,9 \%)$.

Nos dados relacionados a caracterização da relação dos familiares com o parente foram constatados que a maioria dos familiares estavam passando pela experiência de hospitalização de um ente na UTI pela primeira vez $(65,8 \%)$. No que tange ao grau de 
parentesco, a maioria dos entrevistados possuíam laços sanguíneos próximos ao parente hospitalizado, ou seja, a maioria eram filhos $(27,5 \%)$ e irmãos $(25,4 \%)$. Quanto a residir com o ente internado, a maioria dos entrevistados $(59,1 \%)$ não se enquadraram na opção.

No que se refere ao nível de conforto dos familiares na dimensão Interação consigo e cotidiano da ECONF, percebeu-se que existe um maior nível de conforto no item ter disposição física para lidar com essa situação $(3,71 \pm 1,26)$. Em seguida, o item manter-se controlado (a) emocionalmente aparece como o segundo item de maior conforto $(3,36 \pm 1,33)$, em semelhança com manter a rotina com seus familiares $(3,1 \pm 1,41)$, de maneira que esses três itens da dimensão podem ser considerados como os de maior conforto. Os menores níveis de conforto foram encontrados nos itens manter seus hábitos alimentares como antes da internação de seu parente $(2,93 \pm 1,44)$, continuar as minhas atividades habituais (estudo, trabalho, lazer) $(2,73 \pm 1,41)$, ser capaz de relaxar e/ou se distrair durante o período da internação $(2,63 \pm 1,34)$ e manter a rotina de sono como antes da internação do seu parente $(2,63 \pm 1,32)$. Os dois últimos itens apresentaram o mesmo nível de conforto, figurando como os menores quando comparados aos demais itens da dimensão.

\section{CONSIDERAÇÕES FINAIS (ou Conclusão)}

O estudo mostrou que os itens de menor conforto dentro da dimensão interação consigo e cotidiano dizem respeito a vida cotidiana do familiar e seus hábitos, expressos em quatro itens: manter seus hábitos alimentares como antes da internação do seu parente $(2,93 \pm 1,44)$. No contexto hospitalar, muitas vezes, não são destinados a família as acomodações adequadas. As regras, rotinas, horário de visita, alimentação e outros não são devidamente organizados para favorecer ao familiar acompanhante, aspecto que intervém na rotina de autocuidado da família (GOMES, ERDMANN, 2005).

O segundo item foi continuar minhas atividades habituais (estudo, trabalho, lazer, etc) $(2,73 \pm 1,41)$, além da rotina do hospital, o cuidado com a vida cotidiana, muitas vezes, são negligenciados pelo fortalecimento do vínculo com o familiar hospitalizado e a permanência dele no hospital, de maneira que a família passa a viver um grande desgaste emocional e físico (PASSOS, PEREIRA, NITCHKE, 2015).

O terceiro foi ser capaz de relaxar e/ou se distrair durante o período da

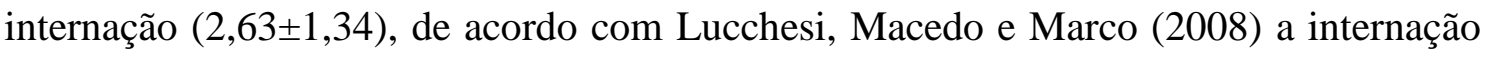
de um ente acaba gerando um choque na família, o que pode promover uma negação, 
sensação de desespero que podem ser maiores do que a capacidade de lidar com a realidade. O último item foi manter a rotina de sono como antes da internação do seu parente $(2,63 \pm 1,32)$, desconforto que pode ser a associado a rotina do hospital que intervêm no sono, repouso e nutrição do familiar (FREITAS, MENEZES, MUSSI, 2015).

Ao considerar a saúde mental dos familiares é preciso pensar em estratégias de autocuidado e coping para vencer o processo de hospitalização sem que a saúde seja comprometida. $\mathrm{O}$ coping centrado no problema tem como objetivo acabar ou amenizar a fonte estressora. Já o centrado na emoção visa descrever a tentativa de substituir ou equilibrar o choque emocional que o estresse promove, decorrente de processos defensivos, onde as pessoas evitam encarar conscientemente a realidade ameaçadora. Seu principal objetivo é modificar o estado emocional do sujeito (LORENCETTI, SIMONETTI, 2005). No caso da hospitalização de um familiar, o sistema pode fazer uso de ambas as estratégias ou até usá-las simultaneamente. (VITÓRIA, ASSIS, 2015).

\section{REFERÊNCIAS}

FREITAS, K. S.;MENEZES, I. G; MUSSI, F.C. Validação da escala de conforto para familiares de pessoas em estado crítico de saúde. Rev. Latino- Am. Enfermagem, v.23, n.4, p. 660-668, 2015.

GOMES, G.C.; ERDMANN, A,L. O cuidado compartilhado entre a família e a enfermagem à criança no hospital: uma perspectiva para a sua humanização. Rev Gaúcha Enferm, v.26, n.1, p. 20-30, 2005.

LORENCETTI, A., \& Simonetti, J. P. (2005). As estratégias de enfrentamento de pacientes durante o tratamento de radioterapia. Rev Latino-Am Enfermagem, 3(6), 944-950.

LUCCHESI, F; Macedo, P. C.M, Marco, M. A. Saúde mental na unidade de terapia intensiva. Rev. SBPH, v.11 n.1 Rio de Janeiro jun. 2008

PASSOS, S.S.S; PEREIRA, A; NITSCHKE, R.G. Cotidiano do familiar acompanhante durante a hospitalização de um membro da família. Acta Paul Enferm. Feira de Santana, 2015; 28(6):539-45.

VITÓRIA, A. L; Assis, C.L. Vivências e estratégias de enfrentamento em acompanhantes de familiar hospitalizado em uma unidade de hospitalar do município de Cacoal-RO. Aletheia 46, jan./abr.2015. 